\title{
Editorial
}

\section{The special issue devoted to papers from the Astrobiology Society of Britain Conference 2008}

\author{
M.J. Burchell \\ Centre for Astrophysics and Planetary Science, School of Physical Sciences, University of Kent, Canterbury, \\ Kent CT2 7NH, UK \\ e-mail:m.j.burchell@kent.ac.uk \\ First published online 27 February 2009
}

In 2008, the Astrobiology Society of Britain (http://www.astrobiologysociety.org) held its third conference: The Living Universe. The meeting was held from 1 to 4 July. The local organizers were the University of Glamorgan, who provided the venue, a brand new purpose built multi-disciplinary centre called the ATRiuM (http:/cci.glam.ac.uk/ campus/), right in the heart of Cardiff. As has become traditional, the programme contained a wide range of research talks on the broad field that is astrobiology. Speakers came from both the UK (the majority) and overseas (the US, Germany and Spain). There were a total of 33 talks, plus opening and closing addresses, with two invited speakers: Professor Chandra Wickramasinghe from Cardiff itself (who spoke about his long involvement in the field), and Professor Barrie Jones from the Open University (who gave a review of exoplanets and their significance for astrobiology).

As well as research talks grouped by themes such as extremophiles, Mars, planets (other), astronomy and so on, the meeting also included the now traditional session on Education and Engagement. Supporting such activities is an essential part of our work as scientists. The new word that emerged this year was 'Engagement', replacing the apparently more passé 'Outreach'. The intention is to aim to not just inform the public, but to encourage them to participate in some fashion.

The conference dinner was held in the spectacular setting of the Cardiff Millennium Stadium (http://www.millenniumstadium.com/306_6555.php). At the dinner, the Society prizes were awarded. Mark Brake, Martin Griffiths, Allan Trow and Catherine Tryfona (the RoCCoTO team at Glamorgan) received a prize for their work on public engagement in Wales. The early career research prize was shared by Euan Monaghan (Kent, graduated weeks earlier) and Danielle Wills (Bristol, still an undergraduate) who were spending the summer working at ESTEC in the Netherlands, and presented a paper at the meeting. The final prize (for research) went to Terry Kee (Leeds) for his work on phosphoric chemistry and its application to astrobiology.

The Society is pleased that selected papers from the meeting are appearing in a special issue of this journal (joining special issues from our previous meetings: vol. 3, issue 4, 2004 and vol. 5, issues 3 and 4, 2006). 
As Chair of the Society, I look forward to our next meeting, to be held in 2010 at a venue to be disclosed on our website in summer 2009.

Guest editor and Chair of the Astrobiology Society of Britain: Mark J. Burchell 